\title{
The Histology of Thyroid Gland of Grey Heron (Ardea cinerea) Regarding Its Age
}

\section{Fiadotau Dzmitry}

Department of Pathological Anatomy and Histology, the Vitebsk State Academy of Veterinary Medicine, Republic of Belarus

\section{Abstract}

The purpose of the research is to determine the features of the microscopic structure of the thyroid gland in a grey heron regarding the age. Material for this study was selected from the grey herons living in natural conditions in Vitebsk and Minsk regions, as well as in the Vitebsk zoological park. Histology of the thyroid gland in the grey heron chicks shows that the body is structurally and functionally mature. The parenchyma of the thyroid gland in Heron was represented by all structural elements. Follicular cells predominantly flat or cubical form the wall of each follicle. In the glands of adult birds there is a smooth increase in the diameter of small, large and medium-sized follicles.

Keywords: Histology, Thyroid gland, grey heron

\section{Introduction}

In the XXI century, more relevant research aimed to study the morphology of birds, Grey Heron (Ardea cinerea Linnaeus, 1758) which is very widely distributed in Belarus.

Heron is not capricious, easily adaptable to environmental factors. The main role of the adaptation of the bird belongs to the endocrine system, particularly the thyroid gland. However, no studies on the structure of the thyroid gland in this species are recorded.

The purpose of the research is to determine the features of the microscopic structure of the thyroid gland in the grey heron regarding its age.

\section{Material and methods}

Material for this study was selected from the grey herons living in natural conditions in Vitebsk and Minsk regions, as well as in the Vitebsk zoological park. For the study 2 age groups $(n=8)$ were collected, chicks before puberty and adult ma- 
ture individuals. The thyroid glands of the studied birds were fixed in a mixture of rouge and $10 \%$ formalin solution. Histological sections of a thickness of 5-7 um were stained with hematoxylin \& eosin. Measurements of the structures of the thyroid gland was performed on a light microscope "Olympus» model BX-41 digital camera «Altra20» and the program «Cell-A». All digital data obtained during the study were treated at «IBM SPSS Statistics 21".

\section{Results}

Histology of the thyroid gland in the grey heron chicks shows that the body is structurally and functionally mature. The gland was covered externally with a thin soft capsule, which departs from the connective septum, reaching to the center and connecting with each other, resulting in a body which has a lobed type of structure. In the thyroid gland, the inter-follicular connective septum layer, together with the capsule form the stroma of the organ. The thickness of the thyroid capsule of the grey heron chicks is $11,67 \pm 2,80$ um, while the adult bird rate increases 1.69 times $(p<0,05)$. Consequently, the age-stromal components occupy a large share of the gland. The inter follicular islands are in the form of clusters up to 14 cells of small size, cubic or round shape, with large spherical nuclei. With age, the capsule of the thyroid gland becomes vascularized.

The parenchyma of the thyroid gland in heron is represented by all structural elements. Follicular cells predominantly flat or cubical form the wall of each follicle. The cell nuclei from rod-to-elongated oval shape and are arranged parallel to the walls of the follicle. In the thyroid glands of the chick grey herons, most of the nuclei of the follicular cells contains 2-3 nucleoli. The cells cytoplasm had bright basophilic nucleus. The height of the cells in chicks is the largest and 6,97 $\pm 0,37$ um. In adults, the follicular wall consists of a single layer of flat and sometimes cubic epithelium.

The follicles in the chick thyroid glands of the grey herons were irregular oval in shape (fig 1), while, adult birds had star-shaped, elongated and other fanciful shapes (fig 2). The cavity is filled with follicular colloid. It is dominated in grey heron chicks in the thyroid follicles which located in the center of the body. The parenchyma of the thyroid gland in adult herons contains almost an equal number of medium and large follicles. Under a microscope, in such cases, can be seen the emergence of young follicles. They seem to bud from the cell- 
parents. These clusters of cells in the field of development of new follicles are called "pads Sanderson" (fig 1). In the thyroid gland of chicks the diameter of small follicles is 19 , $67 \pm 2,07$ um, medium follicles $42,17 \pm 2,23$ um, and large $78,17 \pm 3,31 \mathrm{um}$. In the glands of adult birds there is a smooth increase in the diameter of small, large and medium-sized follicles $(82,75 \pm 2,63 \mathrm{um})$.

\section{Discussion}

Morphometric and histological data on the thyroid gland of different wild bird species are scarce. Breit et al. (1998) found that in contrast to the adult chickens the follicular cells in the thyroid gland were higher and the follicles had a greater volume. We investigated thyroid herons in the summer. Our research results are similar to those scientists Velický et al. (1977) have studied the thyroid in a pheasant in the summer. The pheasant thyroid presents as a relatively quiescent organ with reduced secretory activity in the summer. The follicular epithelium is very low and mostly of the pavement type, while the follicles are unwontedly large and contain an increased amount of colloid. The studies of Fiadotau and Kuchinsky (2013) showed that the thyroid gland of quail chicks are not lobulated. Lobulation of the glands were characteristic only in sexually mature quail.

The finding and interpretation reported in this study provide basic information and indicate that further investigation involving ultrastructure and histochemistry would contribute to a better understanding of these organs and correlates structure and function of the thyroid gland of the Grey Heron (Ardea cinerea Linnaeus, 1758).

\section{References}

Breit S, König HE, Stöger E. The morphology of the thyroid gland in poultry with special regard to seasonal variations // Anat Histol Embryol. 1998 Aug;27(4):271-6.

\section{Velický J, Titlbach M, Rychter Z, Hostýn L. Light and electron mi- croscopy observations in the thyroid gland of the pheasant (Phasianus colchicus L.) // Z Mikrosk Anat Forsch. 1977;91(3):460-74.}

Fiadotau D., Kuchinsky M. Regularities of age-specific structural change of thyroid gland in quails raised industrially // Journal of Animal Husbandry and Veterinary Medicine. 2013; 2(29):49-51. 
Table 1: Morphological indicators of stromal and parenchymal structures of the thyroid gland in a grey heron

\begin{tabular}{|l|c|c|}
\hline \multirow{2}{*}{ Structures } & \multicolumn{2}{|c|}{ Age groups } \\
\cline { 2 - 3 } & chicks & adult bird \\
\hline the thickness of the capsule, um & $11,67 \pm 2,80$ & $19,75 \pm 2,50$ \\
\hline height of follicular cells, um & $6,97 \pm 0,37$ & $3,15 \pm 0,24$ \\
\hline diameter nuclei, um & $4,20 \pm 0,21$ & $1,55 \pm 0,19$ \\
\hline
\end{tabular}

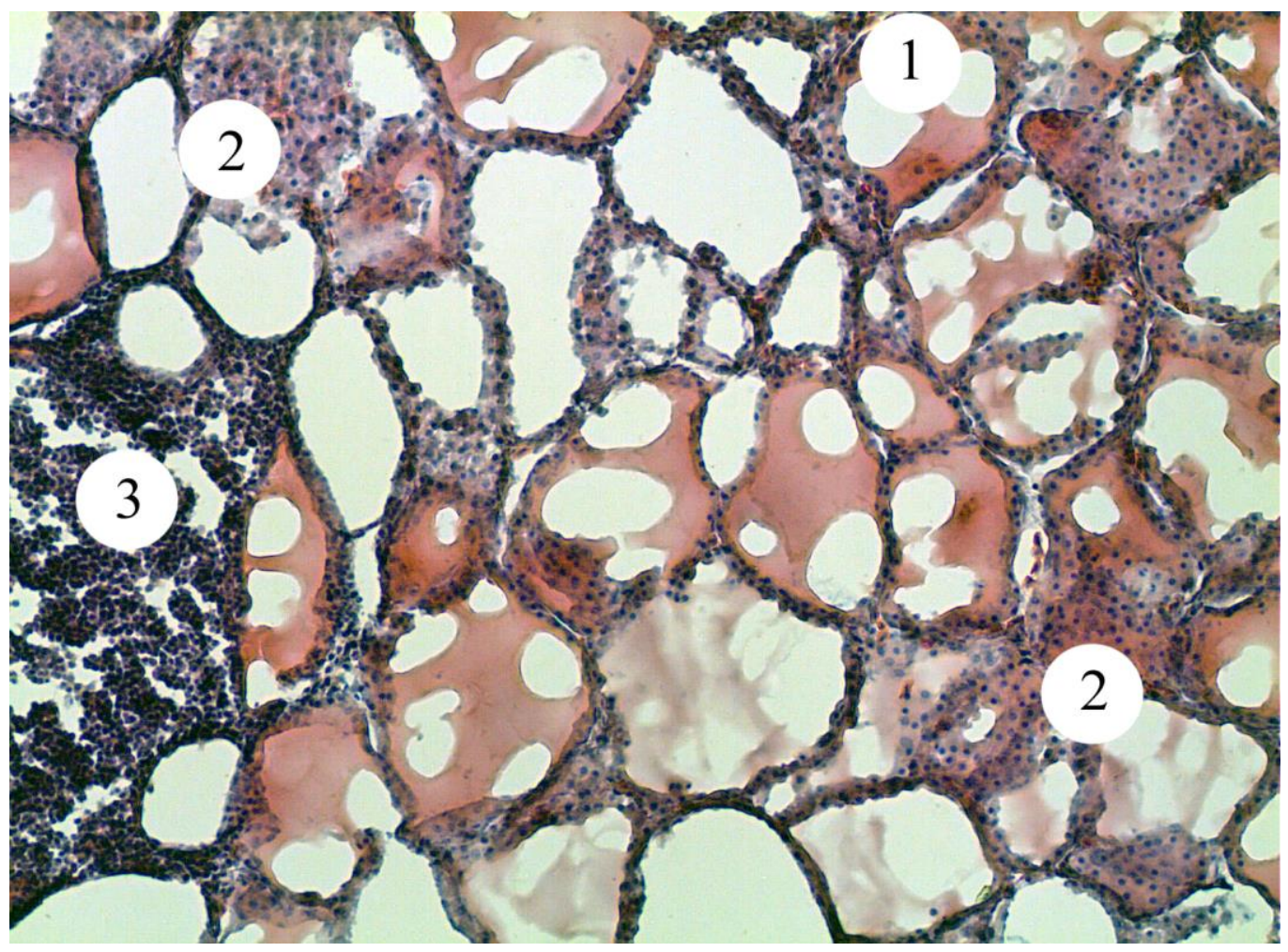

Fig (1): The thyroid gland of a grey heron chick (hematoxylin-eosin, x100).

1 follicles, 2 pads Sanderson, 3 parathyroid cells. 


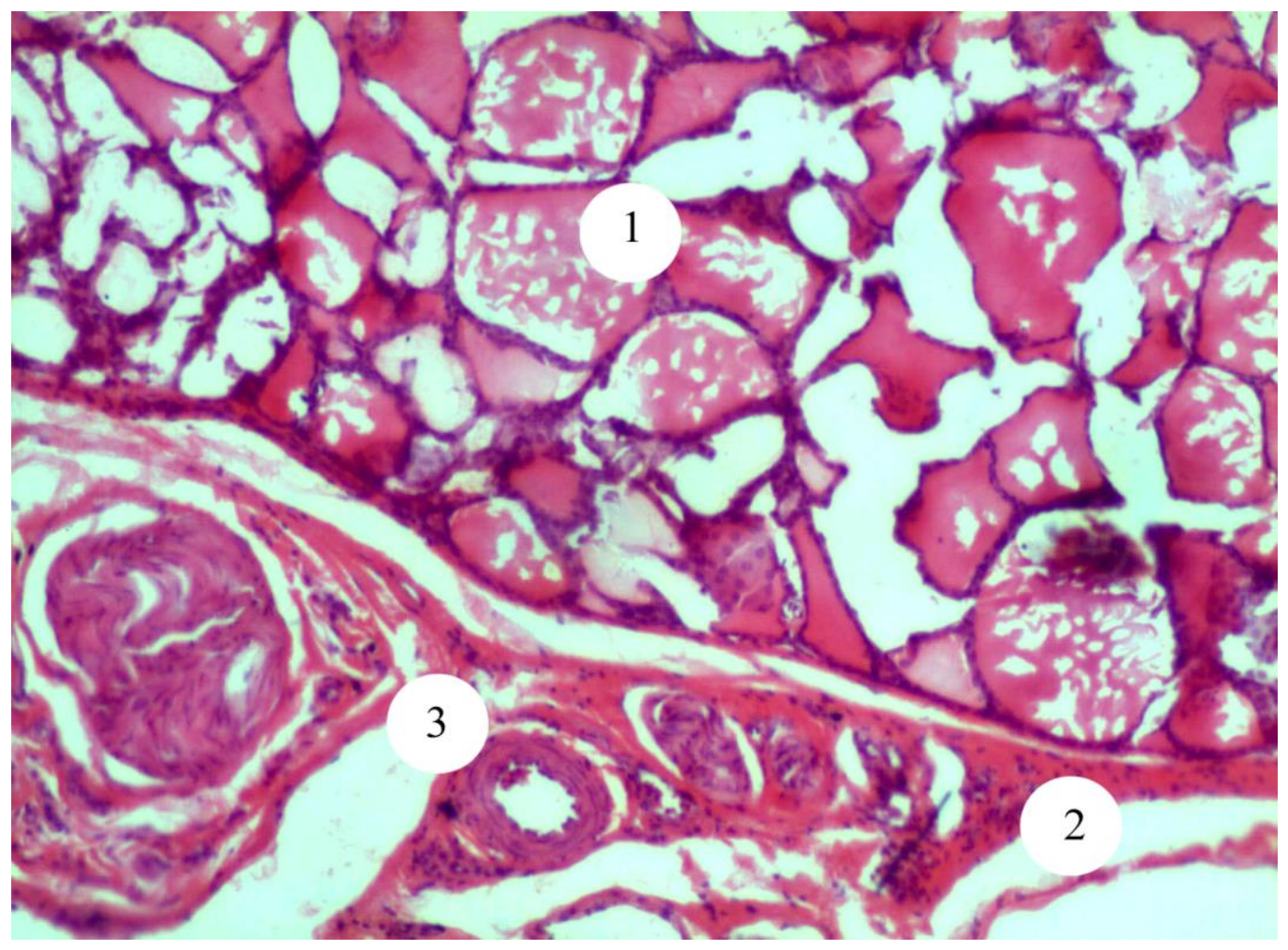

Fig (2): The large follicles and a lot of blood vessels in the thyroid gland of an adult grey heron (hematoxylin-eosin, x100)

1 follicles, 2 capsule, 3 accumulation vessel. 